\title{
The Design for Ultrasonic Ranging System based on Bluetooth Transmission
}

\author{
Zipeng $\mathrm{GUO}^{1,}$, , Jinxia $\mathrm{CHU}^{2, \mathrm{~b}, *}$ \\ ${ }^{1}$ Automobile Institute, Hubei Polytechnic Institute, Xiaogan 432000, China; \\ ${ }^{2}$ School of Fine Art \& Design, Hubei Engineering University, Xiaogan 432000, China \\ a 409461117 @qq.com, b346917126@qq.com \\ ${ }^{*}$ Corresponding author
}

Keywords: STC MCU; Ultrasonic measurement system; signal receiving circuit.

\begin{abstract}
Because of its strong signal intensity and good directivity, ultrasonic can be widely used in the field of industrial control, exploration and measurement, robot localization and security. Based on this, the ultrasonic distance measurement instrument with high precision and miniaturization character has been designed with the core of enhanced 51 microcontroller. The system is mainly composed of a main controller module, ultrasonic transmitting module, ultrasonic receiving module, Bluetooth receiving module and the display module LCD1602 module. In this paper, both the hardware circuit and the system software flow chart has been described, and the design of the system has also been tested, the results show that the ultrasonic ranging system has the advantages of high measuring precision, good accuracy, the measurement relative error is low.
\end{abstract}

\section{Introduction}

Because of its strong signal intensity and good directivity, ultrasonic can be widely used in the field of industrial control, exploration and measurement, robot localization and security[1,3]. The ultrasonic range finder is generally used at home is a special integrated circuit designed, but ASIC cost is relatively high, and that distance is relatively difficult[4,9], the operation is not easy to use, based on this, in this paper, we designs a ultrasonic range finder, used for transmitting and receiving by two independent the ultrasonic probe, to achieve a better effect. The instrument has the advantages of low cost, good performance and broad market prospect, and it has great significance to improve the actual level of electronic distance measurement in our country.

\section{The Overall Diagram for the Designed System}

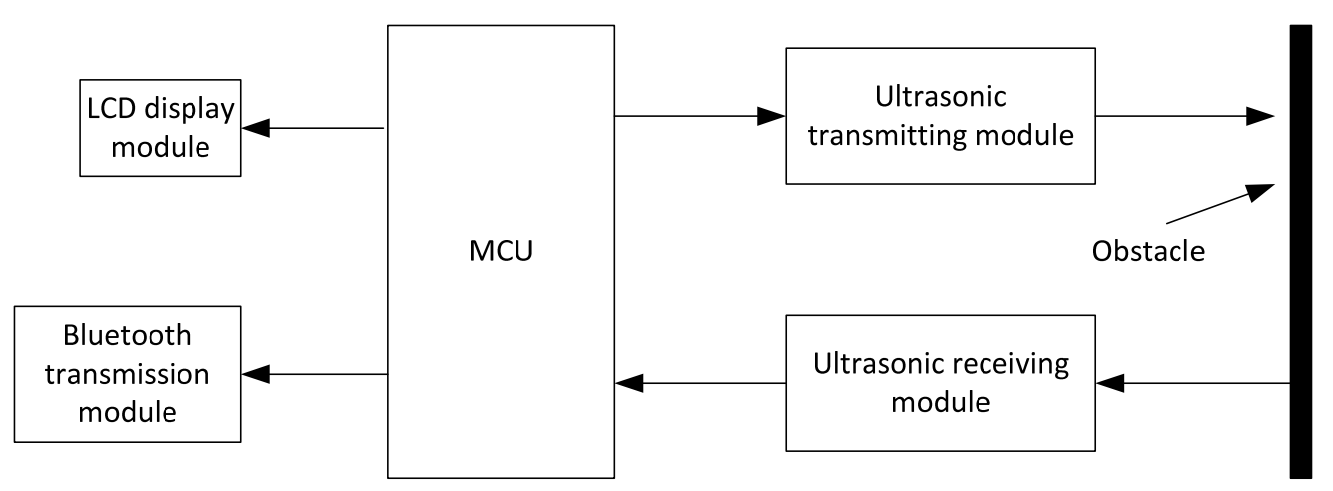

Fig. 1 system diagram for the Ultrasonic measurement system

Ultrasonic ranging system is shown in Figure 1, which consists of four modules: SCM controller, ultrasonic transmitter module, ultrasonic receiving module, LCD display module and Bluetooth transmission module. The controller adopts high performance micro controller STC12C5A60S2, for 
the realization of the entire system of measurement and controlling of signal extraction, processing, calculation and display; ultrasonic transmitting module for ultrasonic transmitting fixed frequency for obstacle; ultrasonic receiving module for receiving the ultrasonic signal reflected back barrier; LCD display module is used to realize the whole system of human-computer interaction Bluetooth; transmission module is used to achieve the remote transmission measurement system.

The ultrasonic receiving module receives the ultrasonic signals reflected by obstacles, and then the test distance is calculated through the internal counter of the micro controller and the ultrasonic velocity. At last, the measured distance can be displayed in the LCD, or transmit to implement remote receiver through the Bluetooth module.

Ultrasonic Signal Transmission Circuit. The ultrasonic transmitting circuit comprises two parts of an ultrasonic generating circuit and an ultrasonic transmitting control circuit. The former uses software to generate $40 \mathrm{KHz}$ ultrasonic signal, the signal through the MCU output pin input to the driving circuit, after driving ultrasonic transducer; the center frequency of CSB40T ultrasonic transducer $40 \mathrm{KHz}$. The method makes full use of the software, the flexibility is good, but need to design a driving current for driving circuit of $100 \mathrm{~mA}$ or above, ultrasonic transmitting circuit as shown in Figure 2, when the input signal is in high level and above by two stage reverse, 1 pin of the CSB40T is high, then become low level after the reverse level; when the input signal is low, on the contrary. In order to achieve the $40 \mathrm{KHz}$ oscillation signal, which drives CSB40T.

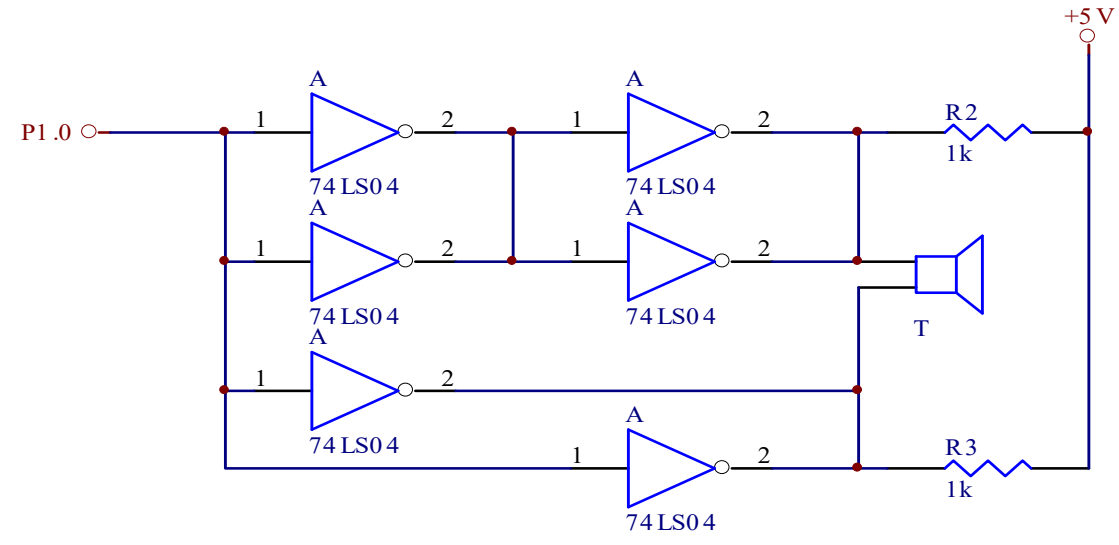

Fig. 2 Ultrasonic signal transmission circuit

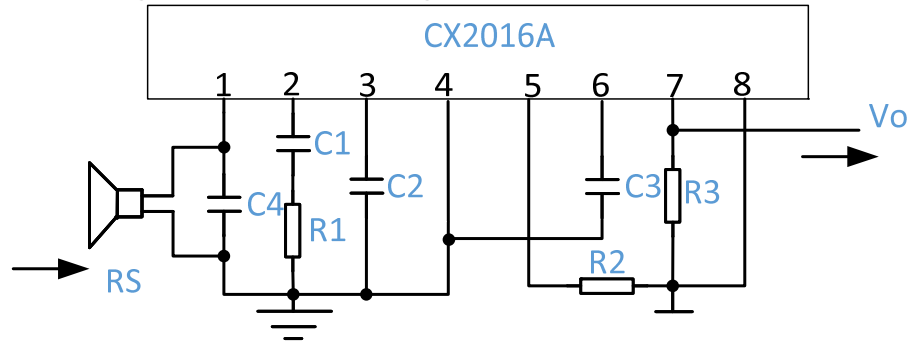

Fig. 3 Ultrasonic signal receiving circuit

Ultrasonic Signal Receiving Circuit. Ultrasonic receiving circuit is shown in Figure 3, to account for the ultrasonic ranging $40 \mathrm{KHZ}$ pulse frequency is close to the commonly used the carrier frequency $38 \mathrm{KHZ}$ for infrared remote control, the chip CX20106A for TV infrared remote control is adopted in this receiving circuit. The experimental results show that the circuit has high sensitivity and strong anti-interference ability. The sensitivity and anti-interference ability of the receiving circuit can be improved by changing the capacitance of the receiving end of the probe. The module can receive the reflected ultrasonic signal, and then send it to the microcontroller for further processing.

The Execution Flow for System Software. The main function of the program is to initialize the system environment. Firstly, set the timer T0 mode of operation for the 16 bit timer counter mode, set the total interrupt enable bit EA and clear the display port P1 and P3. Then send a ultrasonic ultrasonic pulse by calling the subroutine, in order to avoid direct ultrasonic from the transmitter is directly transmitted to the receiver caused by wave triggering, it need delay of about $0.1 \mathrm{~s}$ (which is 
also the ultrasonic range finder will have a minimum detectable distance causes) after the external interrupt 1 receives the returned ultrasonic signal. Due to the use of the $12 \mathrm{MHZ}$ crystal, Count time interval for each record is $1 \mathrm{~s}$. when the main program detects a received success flag, the distance between the object and measure system can be measured through the counter value of T0 (i.e. the ultrasonic round-trip time).

Overall, the executive program contains the following steps:

(1) the initialization of LCD, showing the boot interface for any number, indicating that the measurement did not start.

(2) the continuous launch of the $40 \mathrm{KHZ}$ pulse wave by the microcontroller, immediately start the INT0, the program can be activated after the interruption, waiting for the full value of the timer interrupt, start the receiving program.

(3) echo signal arrives, immediately turn off the counter, capture the value of INT1.

(4) capture count value and call for the calculation program.

(5) display measurement results.

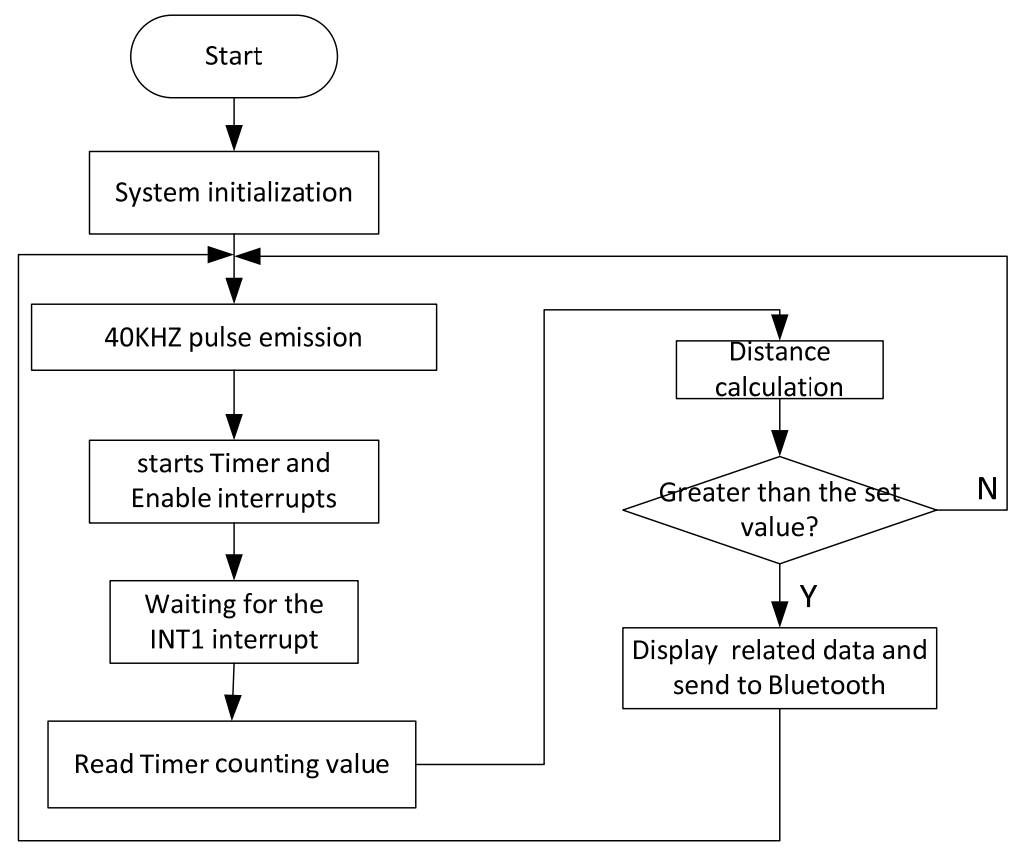

Fig. 4 System software execution flow

\section{Experiment Study for This System}

Table 1 Experimental data for the designed system

\begin{tabular}{ccc}
\hline Standard value/cm & measured value /cm & Relative error \\
\hline 15 & 15.1 & $0.66 \%$ \\
20 & 20.2 & $1 \%$ \\
40 & 40.5 & $1.25 \%$ \\
60 & 61.0 & $1.66 \%$ \\
150 & 152.7 & $1.8 \%$ \\
\hline
\end{tabular}

In view of the above design system, we have carried on the related test experiment, the test range is $0.15 \sim 1.50 \mathrm{~m}$, and each test value is the average value of the measurement results, the experimental data for the designed system is shown in tab. 1 and the following conclusions can be drawn as follows :

(1) the measurement results are accurate, the error is small, and the stability is good, and the average error of the change in the range of $2 \mathrm{~m}$ is not more than $3 \mathrm{~mm}$. 
(2) the farther the distance is, the bigger the relative error is.

\section{Conclusions}

The ultrasonic ranging system is design based on enhanced 51 MCU and CX20106A integrated circuit. the system is composed of ultrasonic transmitting module, ultrasonic receiving module, LCD display module and Bluetooth transmission module. According to the test results of the designed system, the results show that the system has the advantages of high precision and good stability, and has a good market prospect.

\section{Acknowledgement}

We would like to express our thanks to ours students for their valuable discussions and helps to ready for ours experiment. This work has been supported by the key project of Hubei Provincial Department of Education: D20152703.

\section{References}

[1] Muller L J, Franklin A, Ii R W G. Ultrasonic ranging system[J]. Journal of the Acoustical Society of America, 1988, 83(83):2469.

[2] Figueroa J F, Lamancusa J S. A method for accurate detection of time of arrival: Analysis and design of an ultrasonic ranging system[J]. Journal of the Acoustical Society of America, 1992, 91(1):486-494.

[3] Pan S, Haining Z, Fu B, et al. Design of car reversing avoidance system based on ultrasonic ranging[J]. Foreign Electronic Measurement Technology, 2016, 10: 013.

[4] Huang J D, Lee C K, Yeh C S, et al. High-Precision Ultrasonic Ranging System Platform Based on Peak-Detected Self-Interference Technique[J]. IEEE Transactions on Instrumentation \& Measurement, 2011, 60(12):3775-3780.

[5] Yao Z J, Meng Q H, Zeng M. Improvement in the accuracy of estimating the time-of-flight in an ultrasonic ranging system using multiple square-root unscented Kalman filters[J]. Review of Scientific Instruments, 2010, 81(81):104901.

[6] Zhang J Q, Zhang J, Zhao H Y. Design of High-Precision Ultrasonic Ranging System[J]. Applied Mechanics \& Materials, 2014, 563:199-202.

[7] Peng H W, Cheng Y J, Hu Z G, et al. Design of ultrasonic distance-measuring system using temperature compensation methods[J]. Journal of Chemical and Pharmaceutical Research, 2014, 6(6): 2116-2119.

[8] Jackson J C, Summan R, Dobie G I, et al. Time-of-flight measurement techniques for airborne ultrasonic ranging[J]. IEEE transactions on ultrasonics, ferroelectrics, and frequency control, 2013, 60(2): 343-355.

[9] Dionigi M, De Angelis G, Moschitta A, et al. A simple ranging system based on mutually coupled resonating circuits[J]. IEEE Transactions on Instrumentation and Measurement, 2014, 63(5): 1215-1223. 